\title{
ANIMASI INTERAKTIF KESENIAN DAN KEBUDAYAAN JAWA BARAT UNTUK SEKOLAH DASAR
}

\author{
Linda Sari Dewi, Ester Arisawati, Erene Gernaria Sihombing \\ Sekolah Tinggi Manajemen Informatika dan Komputer Nusa Mandiri \\ (STMIK Nusa Mandiri) \\ Jl. Kramat Raya No.18 Jakarta Pusat \\ http://www.nusamandiri.ac.id \\ linda.lrw@nusamandiri.ac.id, esterarisawati@yahoo.com,erene.egs@nusamandiri.ac.id
}

\begin{abstract}
Multimedia aims to present information in the form of a fun, exciting, easy to understand and clear. Then by using interactive animation application as an information medium, Indonesian culture can be delivered using an easy and attractive way. Interactive multimedia learning model is very effective. This can be seen because of the many animated elements. This interactive multimedia learning model will make students do not get bored because students will feel how to play and learn with students will be quicker to capture in the learning takes place, especially to get to know art and culture in western Java. In this interactive animation applications also can increase children's knowledge in order to know more about art and culture located in western Java. In this application contains information cultural arts western Java will students can increase the pride and love of the homeland Indonesia
\end{abstract}

Keywords: Multimedia, Learning Model, Arts and Culture

\begin{abstract}
Abstrak
Multimedia bertujuan untuk menyajikan informasi dalam bentuk yang menyenangkan, menarik, mudah dimengerti, dan jelas. Maka dengan memanfaatkan aplikasi animasi interaktif sebagai media informasi, kebudayaan indonesia dapat disampaikan dengan menggunakan cara yang mudah dan menarik. Model pembelajaran multimedia intaktif ini sangat efektif. Hal tersebut dapat dilihat karena banyaknya unsur animasi. Model pembelajaran multimedia interaktif ini akan membuat siswa tidak bosan karena siswa akan merasakan belajar dengan cara bermain dan siswa akan lebih cepat tangkap dalam pembelajaran berlangsung khususnya untuk mengenal kesenian dan kebudayaan di jawa barat. Dalam aplikasi animasi interaktif ini juga dapat meningkat pengetahuan anak agar lebih mengenal keseni dan kebudayaan yang terdapat dijawa barat. Pada aplikasi ini berisikan informasi-informasi kesenian kebudayaan jawa barat akan siswa dapat meningkatkan rasa bangga dan cinta tanah air indonesia.
\end{abstract}

Kata Kunci: Multimedia, Model Pembelajaran, Kesenian dan Kebudayaan.

\section{PENDAHULUAN}

Indonesia merupakan negara kepulauan yang memiliki banyak keanekaragaman suku, seni, dan budaya. Jawa barat merupakan salah satu kepulauan indonesia yang mempunyai banyak kesenian dan kebudayaan, sehingga kita perlu menjaga kelestariannya. Tetapi kebanyakan kita kurang 
mengetahui hal tersebut. Oleh karena itu perlu kita tanamkan rasa nasionalisme dan cinta tanah air sejak dini khususnya anak-anak usia sekolah dasar melalui pembelajaran kebudayaan dan kesenian jawa barat. Pembelajaran animasi interaktif mengenal kebudayaan jawa barat ini di khusus kan untuk kelas 5 di sekolah dasar. Karena banyaknya siswa tidak mengenal kesenian dan kebudayaan jawa barat. Bila kita tengok pada dunia pendidikan, khususnya tingkat sekolah dasar, semua siswa pasti medapatkan materi pembelajaran mengenai kebudayaan. Kebanyakan sekolah hanya menggunakan media buku untuk mempelajarinya sehingga siswa cepat bosan dengan pembelajaran yang hanya menggunakan media buku. Banyak sekali cara lain yang semestinya dilakukan oleh kalangan guru, salah satunya adalah menggunakan media komputer, atau biasa yang disebut dengan multimedia interaktif.

Perkembangan media interaktif yang merupakan bagian dari media penyampaian informasi saat ini merupakan suatu metode alternatif baru yang bisa dijadikan sebagai alat penyampaian informasi. Secara sederhana, multimedia diartikan sebagai lebih dari satu media. Arti multimedia yang umumnya dikenal ini adalah berbagai macam kombinasi grafik, text, suara, video, dan animasi. Pengabungan ini merupakan satu kesatuan yang secara bersama-sama menampilkan informasi, pesan, atau isi pelajaran. Multimedia bertujuan untuk menyajikan informasi dalam bentuk yang menyenangkan, menarik, mudah dimengerti, dan jelas. Maka dengan memanfaatkan aplikasi animasi interaktif sebagai media informasi, kebudayaan indonesia dapat disampaikan dengan menggunakan cara yang mudah dan menarik[1].

Model pembelajaran multimedia intaktif ini sangat efektif. Hal tersebut dapat dilihat karena banyaknya unsur animasi. Model pembelajaran multimedia interaktif ini khususnya dibidang kesenian dan kebudayaan indonesia dibuat sebagai solusi agar siswa tertarik dan tidak mudah bosan pada saat belajar, selain itu juga mempermudah siswa mengenal sekaligus mengetahui kesenian dan kebudayaan asal jawa barat yang sangat beraneka ragam. Hal ini juga bisa membuat siswa lebih cinta dan bangga dengan kebudayaan yang dimiliki oleh jawa barat.

\section{METODOLOGI PENELITIAN}

Penulis melakukan penerapan metode penelitian untuk memperoleh data-data yang dibutuhkan sehingga penelitian ini dapat diselesaikan dengan baik.

\subsection{Teknik Pengumpulan data}

Ada beberapa metode pengumpulan data yang dipergunakan untuk mendapatkan keterangan-keterangan guna untuk memenuhi kebutuhan dalam penyusunan Karya ilmiah ini adalah sebagai berikut: 
a. Observasi

Yaitu dengan melakukan pengamatan, pencatatan dan pengumpulan data yang dibutuhkan. Pengamatan dilakukan dengan melihat4 langsung kegitan anak sekolah dasar.

b. Wawancara

Teknik ini dimaksudkan untuk memperoleh penjelasan secara menyeluruh dan medalam. Dengan wawancara mendalam diharapkan teridentifikasi berbagai kelebihan, kelemahan, ataupun hambatan dalam pelaksanaan kegiatan penjualan.

c. Studi pustaka

Studi pustaka merupakan sebuah metode untuk menggali informasi dan data yang sudah ada terutama dokumen atau catatan mengenai transaksi penjualan. Metode studi pustaka digunakan untuk membantu penulis dalam penyusunan skrpsi yang ditunjang dengan beberapa buku dan literatur, termasuk data yang berasal dari internet atau website dan lainlain.

\subsection{Model Pengembangan Sistem}

Model pengembangan sistem yang penulis gunakan dalam penulisan yaitu model waterfall. Model waterfall menyedikan pendekatan alur hidup perangkat lunak secara sekuensial atau terurut dimulai dari [2]:

A. Analisa kebutuhan sistem

Analisa merupakan tahapan awal yang dilakukan oleh peneliti dalam mengembangkan sistem. Dalam analisa ini harus mendapatkan beberapa hal yang dianggap menunjang penelitian yang dilakukan, seperti : mencari permasalahan yang ada, mengumpulkan data (data fisik, non fisik), wawancara dan lain-lain. Dalam tahap awal ini penulis dituntut agar benar-benar melakukan penelitian yang terarah untuk membangun media pembelajaran ini.

B. Desain

Desain yang dimaksud bukan hanya tampilan atau interfacenya saja, tetapi yang dimaksud desain dalam model ini adalah desain sistem yang meliputi, alur kerja sistem, cara pengoprasian sistem, hasil keluar (output) dengan menggunakan metode-metode yang disesuaikan dengan analia kebutuhan pada tahap awal untuk menyelesaikan permasalahan dalam pembuatan media pembelajaran secara interaktif ini. Sehingga pihak yang terlibat dalm pembuatan kode program akan dipermudah karena sudah terarah seperti apa sistem ini akan berjalan dan seperti apa alur yang ada didalam sistem maupun diluar sistem.

C. Code generation

Bagian pengodean merupakan bagian para programmer untuk memasukan script kode yang ada pada program macromedia flash 8.0 untuk menghasilkan aplikasi yang telah di desain, kemudian dilakukan pengujian untuk mengetahui apakah masih ada kesalahan pada aplikasi yang akan dibuat. 
D. Testing

Tahap ini adalah tahap testing atau pengujian yang artinya sistem yang telah dibuat dari hasil analisa masalah yang telah melalui tahap-tahap desain, pengodean barulah masuk kedalam tahap pengujian sistem, sehingga akan dapat diketahui seperti apa hasil akhir kinerja sistem yang baru dibuat ini dibandingkan dengan sistem yang lama, kemudian dapat diketahui pula apakah dalam sistem yang baru ini masih ada kelemahan atau tidak.

E. Support

Tahapan ini tidak menutup kemungkinan sebuah perangkat lunak mengalami perubahan ketika sudah dikirimkan ke user. Perubahan bisa terjadi karena adanya kesalahan yang muncul dan tidak terdeteksi saat pengujian atau perangkat lunak harus beradaptasi dengan lingkungan baru. Tahap pendukung atau pemeliharan ini dapat mengulangi proses pengembangan mulai dari tahap analisa spesifikasi untuk perubahan perangkat lunak baru.

\section{HASIL DAN PEMBAHASAN}

\subsection{Karakteristik Software}

Dalam animasi interaktif ini yang akan dibuat terdiri dari 5 menu utama yang dapat kita pilih yaitu, terdapat menu sejarah mengenai jawa barat, menu seni dan budaya, menu soal latihan, menu permainan dan yang terakhir menu keluar. Pada menu seni dan budaya terdapat 8 pilihan menu yang berisikan tentang lagu daerah, tari daerah, alat musik, pakaian, rumah adat, senjata, suku dan yang terkahir adalah objek wisata. Pada menu soal latihan didalamnya terdapat 10 latihan pilihan ganda yang berisikan tentang pertayaan seputar jawa barat dan diterakhir latihan terdapat hasil nilai/score.

\section{Rules}

Pada animasi interaktif ini, siswa/pemain harus terlebih dahulu mempelajari semua materi yang terdapat dimenu sejarah dan menu seni\&budaya yang terdapat dalam animasi tersebut. Setelah itu siswa/ pemain dapat memilih menu soal latihan dan didalam soal latihan terdiri dari 10 soal pilihan ganda dan terdapat score/nilai diakhir pertanyaan.

2. Policy

Ketika siswa/pemain dapat menyelessaikan 10 pertanyaan yang terdapat dimenu soal latihan keluarlah nilai/score dari berapa pertayaan yang telah kita jawab. Didalam animasi terdapat menu permainan untuk para siswa/pemain.

\section{Scenario}

Pertama kali pemain akan diperkenalkan dengan sejarah dan kebudayaan mengenai jawa barat yang terdapat didalam menu, setelah itu pemain akan diminta untuk menjawab soal latihan yang terdiri dari 10 pilihan ganda yang nnti akan terdapat nilai/score di akhir soal latihan. Selain itu siswa/pemain dapat bermain pada menu permainan, siswa akan bermain menyamakan gambar yang tertutup atau disebut dengan memory atau 
mengingat. Semua proses mulai dari sejarah, seni dan budaya, soal latihan, dan permainan adalah sebuah scenario dalam animasi interaktif ini.

4. Event

Pada animasi interaktif ini siswa/pemain diharuskan menjawab 10 soal latihan berupa pilihan ganda yang terdapat dimenu soal latihan dan diakhirnya akan terdapat nilai/score dari hasil jawaban yang telah siswa kerjakan. Selain itu terdapat pemainan yang berupa memory/ mengingat gambar untuk mengasah logika siswa sambil bermain dan tujuan pembelajaran pun tercapai.

5. Roles

Siswa/pemain diharuskan menjawab soal yang terdapat di menu soal latihan tujuannya untuk mengasah seberapa besar pengetahuan\ siswa/pemain dalam mengenal seni dan budaya yang terdapat dijawa barat.

\section{Decision}

Keputusan yang telah dibuat oleh sipembuat animasi ini adalah siswa/pemain harus menyelesaikan soal latihan yang telah disediakan dan dalam permainan sendiri siswa/ pemain harus dapat menyesuaikan gambar dan mengingat gambar mana yang harus dipasangkan dengan yang sama dalam permainan ini juga terdapat waktu sehingga siswa/pemain harus tepat waktu dalam menyelsaikan permainan.

\section{Levels}

Tingkatan yang terdapat dalam animasi interaktif ini terdapat pada pemainan yang telah dibuat, didalamnya terdapat 3 tingkatan jika siswa/pemain dapat menyelesaikan perminan level pertama dengan tepat waktu dengan sendirinya permainan pun langsung berlanjut ke level selanjutnya.

8. Score model

Dalam permainan ini terdapat waktu yang berjalan mundur untuk menyelesaikan permainan, jika siswa/pemain dapat menyelesaikan dengan waktu yang tepat siswa/pemain akan berlanjut ke level selanjutnya, tetapi jika siswa/pemain kehabisan waktu siswa/pemain pun harus mengulang kembali.

9. Symbols

Sebagai penunjuk ke state berikutnya atau ke state sebelumnya digunakan tanda panah. Selain itu, juga terdapat tombol-tombol pada menu yang berupa gambar yang digunakan untuk menuju ke menu-menu yang disediakan.

\subsection{Perancangan Storyboard}

Tahapan berikutnya dalam pembuatan proses animasi interaktif ini adalah membuat storyboard atau rancanan sistem desain halaman. Storyboard atau rancangan desain halaman ini adalah suatu gambaran singkat atau rancangan umum tampilan dari halaman animasi yang dilengkapi dengan penjelasan mengenai halaman animasi tersebut [3]. Storyboard atau rancangan desain halaman ini dapat dibuat dalam potongan- 
potongan gambar. Dalam pembuatan storyboard atau rancangan desain halaman, terdapat rancangan halamannya adalah sebagai berikut:

A. Storyboard Opening

Berikut ini adalah gambaran dari storyboard opening yang dijelaskan pada tabel dibawah ini :

Tabel 1. Storyboard Opening

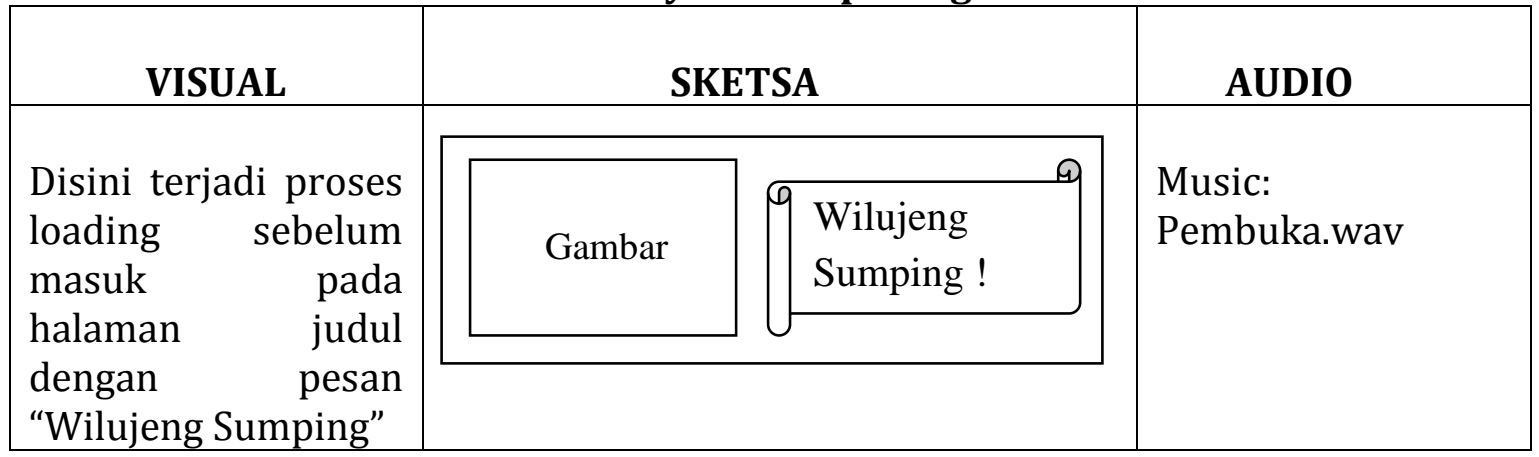

B. Storyboard Menu Utama

Berikut ini adalah gambaran dari storyboard menu utama yang dijelaskan pada tabel dibawah ini :

Tabel 2. Storyboard Menu Utama

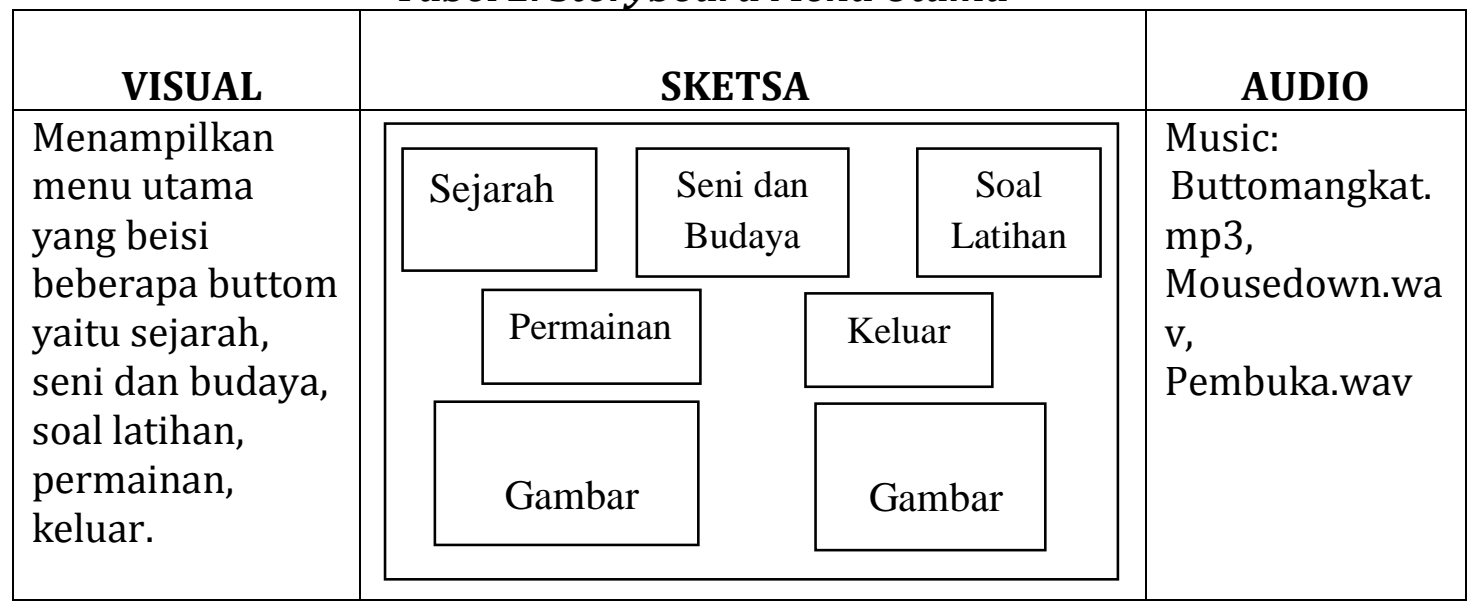


C. Storyboard Menu Seni dan Budaya

Berikut ini adalah gambaran dari storyboard menu seni dan budaya yang dijelaskan pada tabel dibawah ini :

Tabel 3. Storyboard Seni dan Budaya

\begin{tabular}{|c|c|c|c|c|c|}
\hline \multirow{6}{*}{$\begin{array}{l}\quad \text { VISUAL } \\
\text { Menampilkan } \\
\text { buttom lagu } \\
\text { daerah, tarian } \\
\text { daerah, alat musik, } \\
\text { pakaian adat, } \\
\text { rumah adat, } \\
\text { sejarah adat, } \\
\text { senjata, suku adat, } \\
\text { objek wisata, setra } \\
\text { kembali. dan juga } \\
\text { terdapat gambaran } \\
\text { animasi pada menu } \\
\text { ini }\end{array}$} & \multicolumn{4}{|c|}{ SKETSA } & AUDIO \\
\hline & & \multicolumn{2}{|c|}{ Judul } & \multirow{2}{*}{$\begin{array}{l}\text { Pakaian } \\
\text { Adat }\end{array}$} & \multirow{5}{*}{$\begin{array}{l}\text { Buttomangkat.m } \\
\text { p3 } \\
\text { Mousedown.wav } \\
\text { Medley1.wav }\end{array}$} \\
\hline & $\begin{array}{l}\text { Lagu } \\
\text { Daerah }\end{array}$ & Daerah & Musik & & \\
\hline & $\begin{array}{l}\text { Rumah } \\
\text { Adat }\end{array}$ & $\begin{array}{l}\text { Senjata } \\
\text { Adat }\end{array}$ & $\begin{array}{l}\text { Suku } \\
\text { adat }\end{array}$ & $\begin{array}{l}\text { Objek } \\
\text { Wisata }\end{array}$ & \\
\hline & Home & & & & \\
\hline & & & & & \\
\hline
\end{tabular}

\subsection{User Interface}

Pada pembuatan aplikasi ini, memiliki fungsi yang bersifat informasi pengenalan, aplikasi ini dibuat tidak terlalu berlebihan sehingga mampu menyesuaikan dari fungsi aplikasi multimedia ini. Pada beberapa disetiap halamannya juga diberikan latar suara, sehingga mampu menambahkan efek menarik dari aplikasi ini. Aplikasi ini dibuat user friendly, tombol (button) penghubung antar satu frame dengan frame lainnya mudah diketahui, sehingga tidak mempersulit user untuk menggunakannya. Tampilan user interface dari aplikasi ini antara lain :

1. Halaman Pembuka

Halaman pembuka ini atau opening menampilkan teks wilujeng sumping, pada halaman ini akan otomatis masuk pada halaman judul.

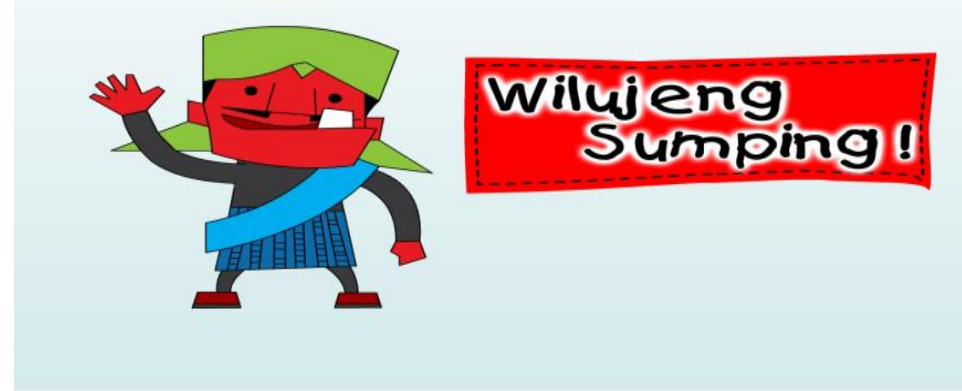

Gambar 1. Halaman Pembuka 


\section{Halaman Menu Utama}

Pada halaman menu utama ini terdapat 5 tombol buttom yang terdiri dari sejarah, seni dan budaya, soal latihan, permain, serta keluar.

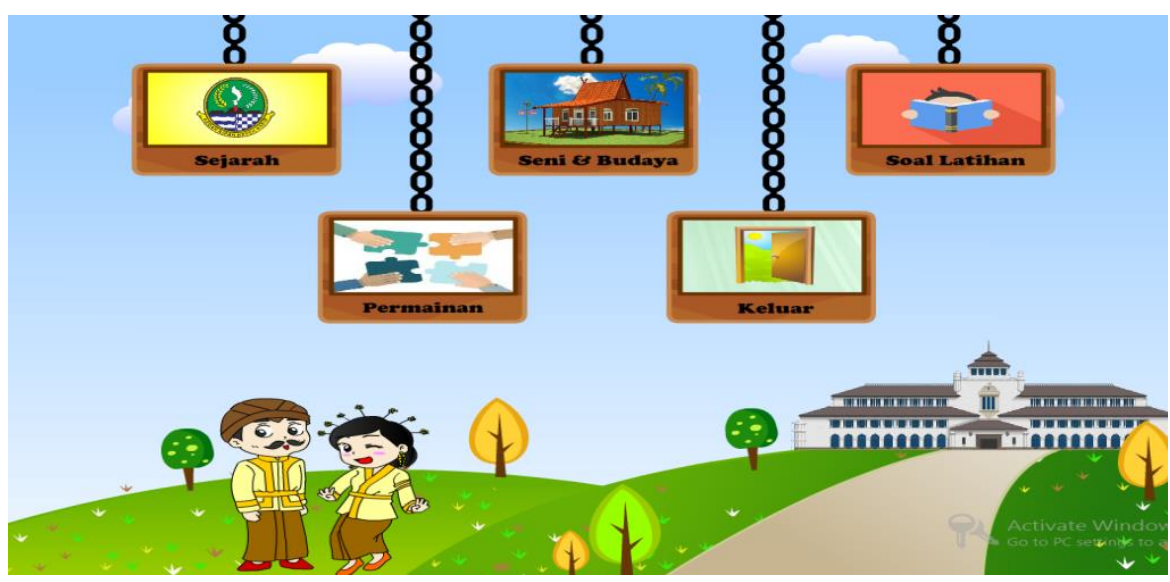

\section{Gambar 2. Halaman Menu Utama}

\section{Halaman Seni dan Budaya}

Pada halaman seni dan budaya ini menampilkan beberapa tombol buttom yaitu lagu daerah, tarian adat, alat musik, pakaian adat, rumah adat, senjata, suku, objek wisata, serta terdapat buttom home untuk kembali ke halaman menu utama.

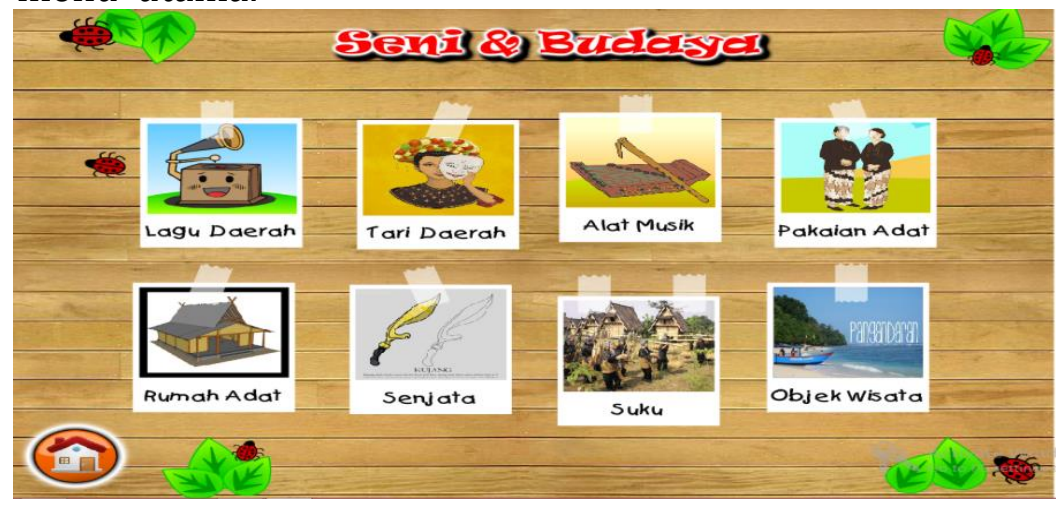

\section{Gambar 3. Halaman Seni dan Budaya}

\subsection{State Transition Diagram}

\section{Scene Menu Utama}

Menggambarkan menu awal aplikasi dimana pertama kali user akan menemui halaman opening yang otomatis akan memasuki halaman judul, dengan klik tombol lanjut maka akan masuk ke menu utama yang terdapat pilihan, yaitu: tombol sejarah, seni dan budaya, soal latihan, permainan, keluar. 


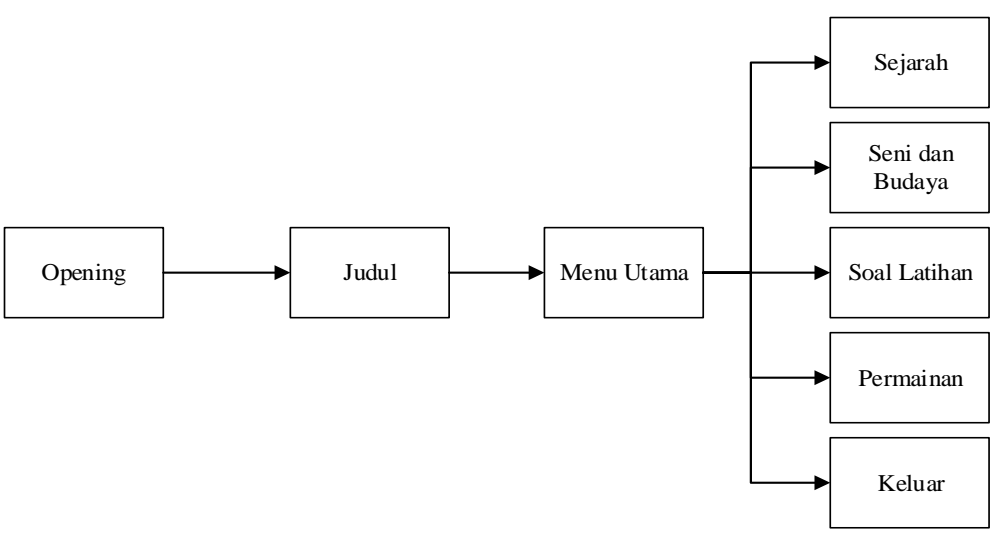

Gambar 4. State Transition Diagram Menu Utama

\section{Scene Menu Seni dan Budaya}

Didalam scene ini terdapat beberapa pilihan tombol menegenai seni dan kebudayaan jawa barat yaitu : tombol lagu daerah, tari daerah, alat musik, pakaian, rumah adat, senjata adata, suku adat, dan objek wisata. Dimasing-masing tombol tersebut akan menjelaskan masing-masing dari seni dan budaya jawa barat.

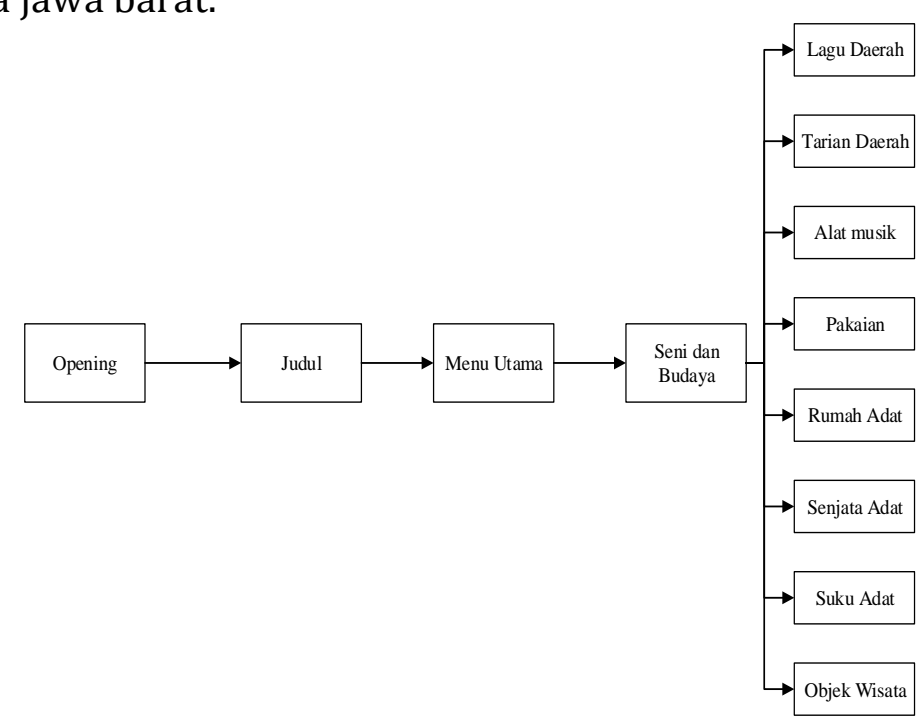

Gambar 5. State Transition Diagram Menu Seni dan Budaya

\subsection{Testing}

Animasi interaktif yang telah dibuat ini, selanjutnya diuji memalui teknik pengujian perangkat lunak meliputi pengujian white box dan black box.

\section{A. White Box}

White box testing adalah cara pengujian dengan melihat kedalam modul untuk meneliti kode-kode program yang ada, dan menganalisis apakah ada kesalahan atau tidak [4]. Jika ada modul ada yang menghasilkan output yang tidak sesuai dengan proses bisnis yang dilakukan maka baris- 
baris program, variable, dari parameter yang terlibat pada unit tersebut akan dicek satu persatu dan diperbaiki, kemudian di compile.

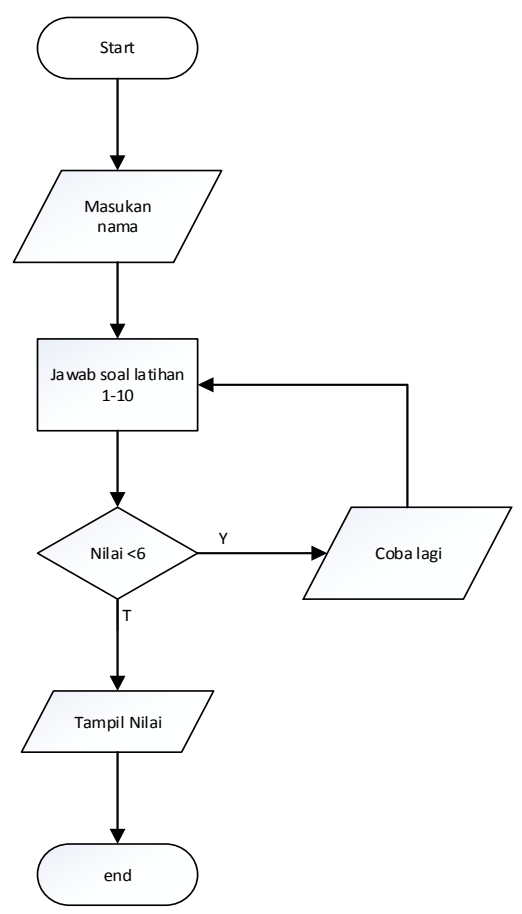

\section{Gambar 6. Bagan Alir Soal Latihan}

Dibawah ini merupakan grafik alir dari soal latihan pada animasi interaktif yang telah dibuat:

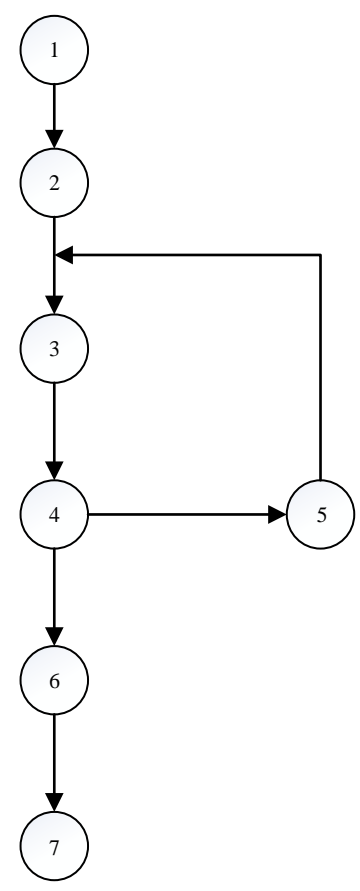

\section{Gambar 7. Grafik Alir Soal Latihan}

Kompleksitas Siklomatis (pengukuran kuantitatif terhadap kompleksitas logis suatu program) dari grafik alir dapat diperoleh dengan perhitungan : 


$$
V(G)=E-N+2
$$

Dimana :

$\mathrm{E}=$ Jumah edge grafik alir yang ditandakan dengan gambar panah $\mathrm{N}=$ Jumlah simpul grafik alir yang ditandakan dengan gambar lingkaran [5] Sehingga kompleksitas siklomatisnya $\mathrm{V}(\mathrm{G})=7-7+2=2$

Basis set yang dihasilkan dari jalur independent secara linier adalah jalur sebagai berikut :

$1-2-3-4-6-7$

$1-2-3-4-5-3-4--6-7$

Ketika aplikasi dijalankan, maka terlihat bahwa salah satu baris set yang dihasilkan adalah 1-2-3-4-6-7 dan terlihat bahwa simpul telah dieksekusi satu kali.

Berdasarkan pengamatanketentuan tersebut dari segi kelayakan softwa $r e$, sistem ini telah memenuhi syarat.

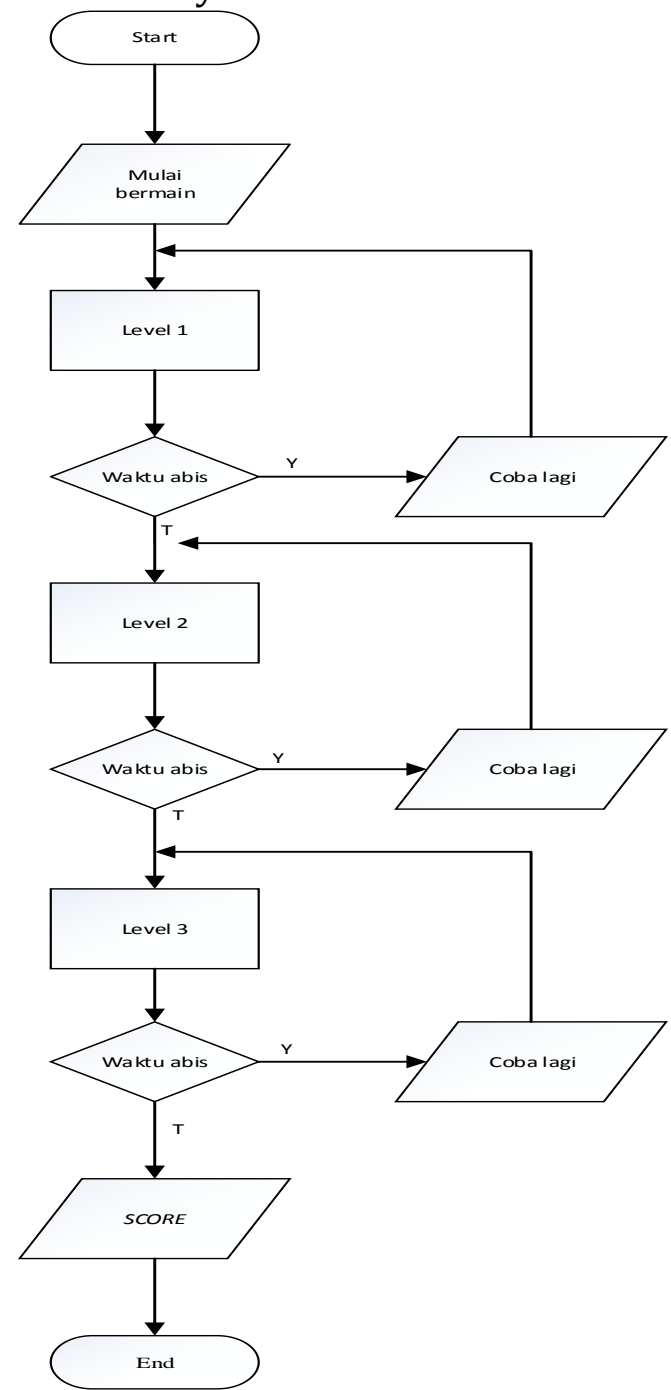

Gambar 8. Bagan Alir Permainan 
Dibawah ini merupakan grafik alir dari permain pada animasi interaktif yang telah dibuat:

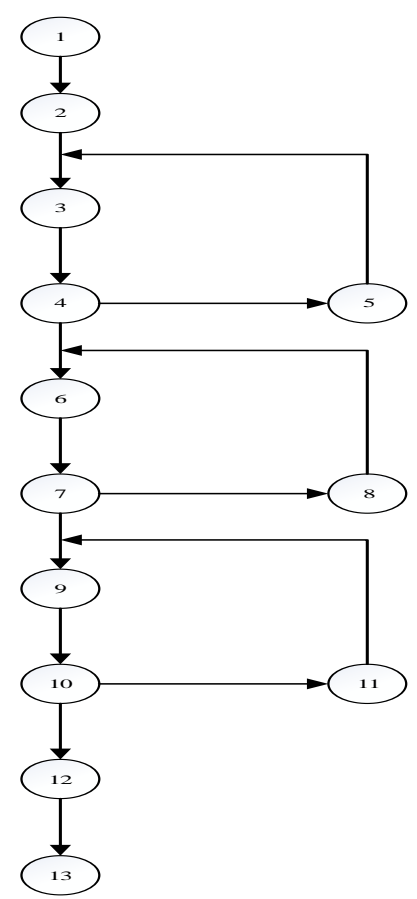

\section{Gambar 9. Grafik Alir Permainan}

Kompleksitas Siklomatis (pengukuran kuantitatif terhadap kompleksitas logis suatu program) dari grafik alir dapat diperoleh dengan perhitungan :

$$
V(G)=E-N+2
$$

Dimana :

$\mathrm{E}=$ Jumah edge grafik alir yang ditandakan dengan gambar panah

$\mathrm{N}=$ Jumlah simpul grafik alir yang ditandakan dengan gambar lingkaran[5].

Sehingga kompleksitas siklomatisnya

$\mathrm{V}(\mathrm{G})=15-13+2=4$

Basis set yang dihasilkan dari jalur independent secara linier adalah jalur sebagai berikut :

$1-2-3-4-6-7-9-10-12-13$

$1-2-3-4-5-3-4-6-7-9-10-12-13$

$1-2-3-4-6-7-8-6-7-9-10-12-13$

1-2-3-4-6-7-9-10-11-9-10-12-13

Ketika aplikasi dijalankan, maka terlihat bahwa salah satu baris set yang dihasilkan adalah 1-2-3-4-6-7-9-10-12-13 dan terlihat bahwa simpul telah dieksekusi satu kali.

Berdasarkan pengamatanketentuan tersebut dari segi kelayakan softwa re, sistem ini telah memenuhi syarat. Adapun untuk level 2 dan 3, alur jalannya permainan sama dengan level 1 , hanya berubah pada perbedaan jenis soal. Jadi dapat dikatakan bahwa hasil pengujian untuk level 2 dan 3 juga telah memenuhi syarat. 


\subsection{Hasil Pengolahan Data Kuesioner}

Pada pembuatan program animasi interaktif ini dilakukan wawancara langsung dengan siswa/siswi dan pada guru di SDN Sukamaju 10 mengenai program animasi yang telah dibuat. Kuesioner diberikan kepada 30 siswa/siswi tentang bagaimana pendapat mereka setelah menjalankan program animasi interaktif, yang terdiri dari 10 pertanyaan.

Berikut ini adalah bagan dari Kuesioner Aplikasi Pembelajaran Membaca untuk siswa/siswi :

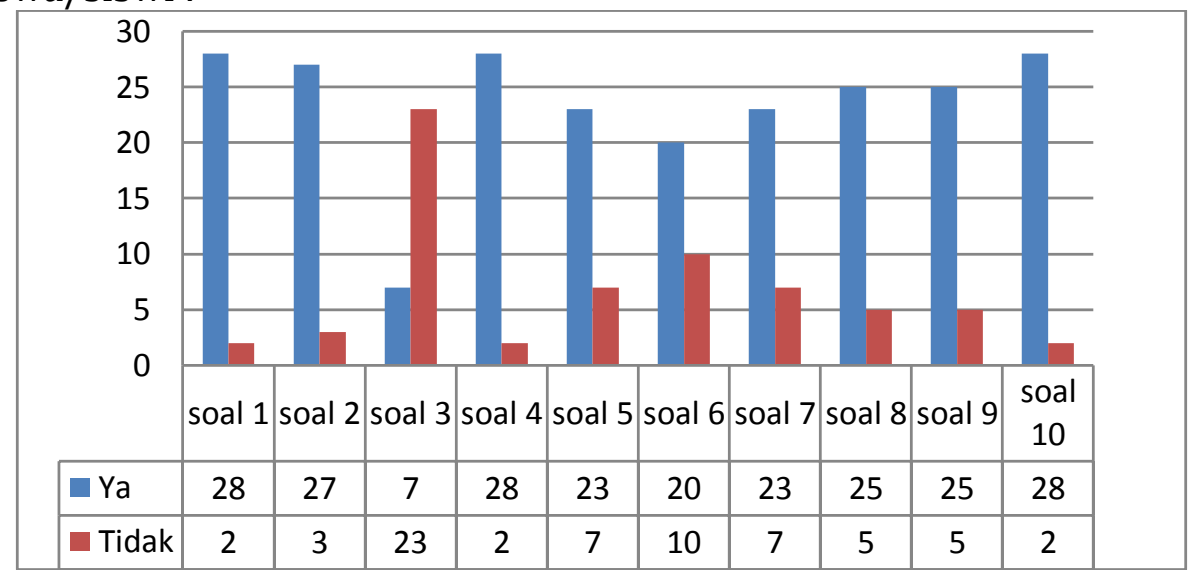

\section{Gambar 10. Tampil Grafik Kuesioner para siswa/siswi}

Dari hasil kuesioner pada gambar 10 dapat diambil kesimpulan bahwa sebagian besar siswa/siswi dapat menggunakan aplikasi ini dengan mudah, dapat membantu dalam pelajaran pengenalan kesenian dan kebudayaan jawa barat, lebih tertarik didalam pelajaran ini, dapat membuat para siswa/siswi lebih kreatif dalam proses belajar dan meningkatkan minat belajar siswa sehingga meningkatnya pengetahuan siswa/siswi akan kesenian dan kebudayaan jawa barat.

\section{SIMPULAN}

Adapun simpulan dari karya ilmiah ini adalah:

1. Belajar dengan menggunakan animasi membuat anak-anak tidak merasa jenuh dan bosan, karena disajikan dalam bentuk tampilan yang menarik.

2. Aplikasi ini ditunjukan kepada anak sekolah dasar agar mereka mudah untuk memahami kebudayaan jawa barat.

3. Latihan yang terdapat dalam program ini merupakan cara mengukur tingkat pemahaman anak didik dalam menerima dan memahami materi yang telah disampaikan.

4. Dengan metode belajar menggunakan animasi seperti ini akan menarik minat anak-anak agar mau untuk memepelajari kebudayaan jawa barat.

5. Aplikasi animasi interaktif ini dapat dengan mudah disajikan untuk anak-anak karna pengunaanya memang saat baik untuk perkembangan belajar anak. 


\section{DAFTAR PUSTAKA}

[1] Darma, Jarot. S dan Shenia Ananda. 2009. Buku Pintar Menguasai Multimedia. Jakarta : Mediakita.

[2] Madcoms. 2009. Panduan Lengkap Editing Video dengan Adobe Primiere Pro CS4. Yogyakarta: ANDI.

[3] Rizky, Soetam, 2011. Konsep Dasar Rekayasa Perangkat lunak. Jakarta : PT. Prestasi Pustaka Raya.

[4] Enterprise, Jubilee. 2010. 30 Bisnis Berbasis Ide Bagi Siapapun. Jakarta : PT. Elex Media Komputindo.

[5] Kurnia, Ganjar dan Arthur S. Nalan. 2003. Dekarya ilmiah Kesenian Jawa Barat. Bandung : Pusat Dinamika Pembangunan UNPAD. 